\title{
Environmental DNA metabarcoding for monitoring metazoan biodiversity in Antarctic nearshore ecosystems
}

\author{
Laurence J Clarke ${ }^{\text {Corresp., } 1,2}{ }^{2}$, Leonie Suter ${ }^{1}$, Bruce E Deagle ${ }^{3}$, Andrea M Polanowski ${ }^{1}$, Aleks Terauds ${ }^{1}$, Glenn J \\ Johnstone $^{1}$, Jonathan S Stark ${ }^{1}$ \\ 1 Australian Antarctic Division, Kingston, Tasmania, Australia \\ 2 Institute for Marine and Antarctic Studies, University of Tasmania, Hobart, Tasmania, Australia \\ ${ }^{3}$ Commonwealth Scientific and Industrial Research Organisation, Hobart, Tasmania, Australia \\ Corresponding Author: Laurence J Clarke \\ Email address: laurence.clarke@aad.gov.au
}

Antarctic benthic ecosystems support high biodiversity but their characterization is limited to a few well-studied areas, due to the extreme environment and remoteness making access and sampling difficult. Our aim was to compare water and sediment as sources of environmental DNA (eDNA) to better characterise Antarctic benthic communities and further develop practical approaches for DNA-based biodiversity assessment in remote environments. We used a cytochrome $c$ oxidase subunit I (COI) metabarcoding approach to characterise metazoan communities in 26 nearshore sites across 12 locations in the Vestfold Hills (East Antarctica) based on DNA extracted from either sediment cores or filtered seawater. We detected a total of 99 metazoan species from 12 phyla across 26 sites, with similar numbers of species detected in sediment and water eDNA samples. However, significantly different communities were detected in the two sample types at sites where both were collected (i.e., where paired samples were available). For example, nematodes and echinoderms were more likely to be detected exclusively in sediment and water eDNA samples, respectively. eDNA from water and sediment core samples are complementary sample types, with epifauna more likely to be detected in water column samples and infauna in sediment. More reference DNA sequences are needed for infauna/meiofauna to increase the proportion of sequences and number of taxa that can be identified. Developing a better understanding of the temporal and spatial dynamics of eDNA at low temperatures would also aid interpretation of eDNA signals from polar environments. Our results provide a preliminary scan of benthic metazoan communities in the Vestfold Hills, with additional markers required to provide a comprehensive biodiversity survey. However, our study demonstrates the choice of sample type for eDNA studies of benthic ecosystems (sediment, water or both) needs to be carefully considered in light of the research or monitoring question of interest. 


\section{Environmental DNA metabarcoding for monitoring}

\section{2 metazoan biodiversity in Antarctic nearshore}

\section{3 ecosystems}

4

5 Laurence J. Clarke ${ }^{1,2}$, Leonie Suter ${ }^{1}$, Bruce E. Deagle ${ }^{3}$, Andrea M. Polanowski ${ }^{1}$, Aleks Terauds ${ }^{1}$,

6 Glenn J. Johnstone ${ }^{1}$, Jonathan S. Stark ${ }^{1}$

7

$8{ }^{1}$ Australian Antarctic Division, Kingston, Tasmania, Australia

92 Institute for Marine and Antarctic Studies, University of Tasmania, Hobart, Tasmania,

10 Australia

$11{ }^{3}$ Commonwealth Scientific and Industrial Research Organisation, Hobart, Tasmania, Australia

13 Corresponding Author:

14 Laurence Clarke ${ }^{1}$

15 Australian Antarctic Division, 203 Channel Highway, Kingston, Tasmania, 7050, Australia

16 Email address: laurence.clarke@aad.gov.au 


\section{Abstract}

18 Antarctic benthic ecosystems support high biodiversity but their characterization is limited to a

19 few well-studied areas, due to the extreme environment and remoteness making access and

20 sampling difficult. Our aim was to compare water and sediment as sources of environmental

21 DNA (eDNA) to better characterise Antarctic benthic communities and further develop practical

22 approaches for DNA-based biodiversity assessment in remote environments. We used a

23 cytochrome $c$ oxidase subunit I (COI) metabarcoding approach to characterise metazoan

24 communities in 26 nearshore sites across 12 locations in the Vestfold Hills (East Antarctica)

25 based on DNA extracted from either sediment cores or filtered seawater. We detected a total of

2699 metazoan species from 12 phyla across 26 sites, with similar numbers of species detected in

27 sediment and water eDNA samples. However, significantly different communities were detected

28 in the two sample types at sites where both were collected (i.e., where paired samples were

29 available). For example, nematodes and echinoderms were more likely to be detected exclusively

30 in sediment and water eDNA samples, respectively. eDNA from water and sediment core

31 samples are complementary sample types, with epifauna more likely to be detected in water

32 column samples and infauna in sediment. More reference DNA sequences are needed for

33 infauna/meiofauna to increase the proportion of sequences and number of taxa that can be

34 identified. Developing a better understanding of the temporal and spatial dynamics of eDNA at

35 low temperatures would also aid interpretation of eDNA signals from polar environments. Our

36 results provide a preliminary scan of benthic metazoan communities in the Vestfold Hills, with

37 additional markers required to provide a comprehensive biodiversity survey. However, our study

38 demonstrates the choice of sample type for eDNA studies of benthic ecosystems (sediment, 
39 water or both) needs to be carefully considered in light of the research or monitoring question of

40 interest.

41

\section{Introduction}

43 Antarctic benthic communities have high biodiversity and high levels of endemism (Aronson et 44 al. 2007), but remain poorly characterised (Halanych \& Mahon 2018). For example, Antarctica 45 supports over $10 \%$ of the world's described pycnogonida (sea spider) diversity, much of which is endemic (Barnes \& Peck 2008). Antarctic benthic biodiversity may have been underestimated to

47 date, as a series of phylogenetic studies highlight the number of cryptic species within lineages

48 previously thought to have circumpolar distributions (reviewed by Kaiser et al. 2013). Antarctic environments are increasingly under pressure from both global and local human activities. Increasing human activity in Antarctica, linked to both national scientific programs and tourism, is likely to impact nearshore environments and benthic communities (Tin et al.

52 2008). $76 \%$ of buildings in Antarctica are in the accessible ice-free areas within $5 \mathrm{~km}$ of the coast 53 (Brooks et al. 2019), increasing the likelihood of human impacts on Antarctic shallow water 54 nearshore environments (Stark et al. 2014a), which are thought to be relatively rare in Antarctica 55 (Clark et al. 2015). Antarctic ecosystems, both terrestrial and marine, are particularly susceptible 56 to introduction of non-indigenous and invasive species in the face of ongoing climate change 57 (Aronson et al. 2007; Chown et al. 2012). Preserving Antarctic benthic communities in the face 58 of increased human activity, invasive species and climate change requires effective tools for 59 rapid, high-throughput biodiversity assessments and monitoring (Halanych \& Mahon 2018). 60 DNA metabarcoding shows promise as a method for rapid biodiversity assessment.

61 Metabarcoding uses high-throughput sequencing of taxonomically-informative DNA barcoding 
62 genes to identify the taxa present in a mixed sample (Hebert et al. 2003; Ji et al. 2013).

63 Metabarcoding can avoid some of the challenges of traditional survey methods, including time-

64 consuming morphology-based identification (Deagle et al. 2018; Leduc et al. 2019), expensive

65 underwater visual surveys (Smith et al. 2015; Stat et al. 2019), and less reliance on taxonomic

66 expertise (Ji et al. 2013). Metabarcoding is often applied to DNA extracted from environmental

67 samples such as water, soil or sediment, known as environmental DNA or eDNA (Thomsen et al.

68 2012). Environmental DNA in benthic environments can come from excreted faeces, mucous,

69 and gametes; shed cells and scales; degrading tissue (e.g. moults and carcasses) and whole live

70 organisms (Taberlet et al. 2018).

71 Several studies have now applied DNA metabarcoding to study Antarctic benthic communities,

72 typically focussing on the meiofauna (taxa in the size range $\sim 45-500 \mu \mathrm{m}$ ). Each of these used

73 sediment samples, including deep-sea sediment (Sinniger et al. 2016), from either the Antarctic

74 Peninsula (Fonseca et al. 2017; Sinniger et al. 2016; Vause et al. 2019), or across West Antarctic

75 sites (Brannock et al. 2018). These studies found environmental DNA from Antarctic sediments

76 is dominated by typical benthic taxa (e.g., nematodes, arthropods, annelids), and sediment eDNA

77 and morphology-based approaches yielded similar findings when comparing two Antarctic

78 Peninsula sites, but with different taxa driving the results (Vause et al. 2019). However, the focus

79 on sediment to date raises the question: can eDNA extracted from water samples be used to

80 characterise Antarctic benthic communities?

81 A water eDNA approach has several potential benefits relevant to fieldwork in remote and harsh

82 environments like Antarctica. Water samples for eDNA analysis are simpler and faster to collect

83 than sediment cores, particularly important for difficult-to-access sites where time on-site is

84 limited. Similarly, water eDNA can potentially be used to study both soft- and hard-bottom 
85 communities, whereas a sediment-based approach is largely restricted to soft-bottom

86

87

communities. However, it is not clear whether water eDNA samples are as useful as sediment samples for characterising benthic biodiversity. Indeed, Holman et al. (2019) found higher DNAbased diversity in nearshore sediment than water eDNA samples at four urban coastal sites in the United Kingdom, and two recent studies found less than $10 \%$ overlap between molecular Operational Taxonomic Units (OTUs) from sediment and benthic water samples (Antich et al. 2020; Brandt et al. 2021). Similarly, Koziol et al. (2019) detected similar numbers of animal taxonomic families in water and sediment eDNA samples, but the number of families detected in the different samples types differed across phyla. For example, more polychaete families (annelids) were detected in sediment samples, but more ascidians (tunicates) were detected in DNA extracted from water.

The aim of this study was to compare water and sediment as eDNA sources for rapid, practical biodiversity assessment for nearshore benthic environments to further inform knowledge of these environments in the Vestfold Hills, East Antarctica. We analysed DNA extracted from sectioned sediment cores and filtered-water samples from sites across the Vestfold Hills region, in the first DNA metabarcoding study of East Antarctic benthic communities. The most suitable sample type for DNA-based biodiversity assessment would yield a high proportion of metazoan reads (for efficiency) and the greatest species richness, whilst reflecting the community composition present at the site (which is not examined here). Our study addressed three main questions: (1) Are there differences between sediment and water eDNA samples in terms of (a) number of reads assigned to metazoans, non-metazoans, and unclassified, (b) the number of metazoan species detected, (c) metazoan community composition?; (2) Does eDNA-based species richness decrease with sediment depth, similar to trends observed in morphology-based studies 
108 (Filgueiras et al. 2007; Vanhove et al. 2009)?; (3) Do environmental parameters (e.g. depth,

109 distance to open ocean) influence community composition in water eDNA? We also discuss the

110 utility of these methods for benthic monitoring and provide recommendations for sampling and

111 marker choice (based on in silico analyses) for future applications of DNA metabarcoding.

113 Materials \& Methods

\section{Sample collection}

115 Field work permits were granted by the Australian Antarctic Division (ATEP 19-20-5097).

116 Water column eDNA samples were collected from 12 nearshore locations around Davis station

117 (26 sites, 1-4 sites per location, Figure 1). Additionally, replicate samples were collected from

118 six sites, although one pair was collected one day apart, indicating day-to-day variability rather

119 than being a true biological replicate. For each sample, $2 \mathrm{~L}$ water was collected approximately 1

$120 \mathrm{~m}$ from the bottom (depths: 8.4-39 m) using a Niskin bottle. Each water sample was transferred

121 to a $2 \mathrm{~L}$ plastic collection bottle and filtered through a Supor $0.45 \mu \mathrm{M} 47 \mathrm{~mm}$ membrane filter

122 (Pall Life Sciences, New York, NY, USA) using a Sentino pump (Pall Life Sciences) either in

123 the field or on return to Davis station the same day. Negative controls (2 L Milli-Q water) were

124 also filtered at one site (Bandits) or in the Davis station lab to monitor contamination. After

125 filtration, filter membranes were cut in half and stored at $-80^{\circ} \mathrm{C}$ as soon as possible. Collection

126 bottles were cleaned with $10 \%$ bleach to prevent cross-contamination of samples and rinsed at

127 least twice with Milli-Q water between samples. At the sampling site, bottles were rinsed twice

128 with water from the collection site. Tweezers, filter funnel and the pump base were also cleaned

129 with $10 \%$ bleach between samples. 
130 Sediment was collected for genetic analysis from six locations (10 sites, 1-2 sites per location,

131 Figure 1, Table S1,) using a Kajak gravity corer (KC Denmark A/C, 50 mm core diameter).

132 Water eDNA samples were also collected from all sites with sediment cores, although two of

133 these water samples yielded too few metazoan reads and were not analysed (see Results).

134 Sediment samples from two sites (Abatus Bay and Wharf) were limited to material in the 'core

135 catcher' closing system and were not sectioned. At the eight sites where a true sediment core was

136 obtained, the top of each sediment core was sectioned into $20 \mathrm{~mm}$ lengths down to $100 \mathrm{~mm}$ (if

137 available) using a fraction tray attached to the top of the core tube, transferred to $250 \mathrm{~mL}$ jars and

138 stored at $-20{ }^{\circ} \mathrm{C}$ for transport to Australia. Sediment samples $(n=42)$ were thawed, homogenized

139 and approximately $250 \mathrm{mg}$ (wet weight) of sediment transferred to Eppendorf tubes for DNA

140 extraction.

141

142 DNA extraction, PCR-amplification and high-throughput sequencing

143 DNA was extracted from half of each filter and sediment samples using the QIAGEN DNeasy

144 PowerSoil kit. We chose the PowerSoil kit as it provides high quality and quantities of DNA

145 from multiple sample types, including filtered water and sediment (Hermans et al. 2018). We

146 followed the manufacturer's instructions with the exception that samples were homogenized in

147 the PowerBead tube using a FastPrep-24 (MP Biomedicals) at $4.5 \mathrm{~m} / \mathrm{s}$ for 45 seconds.

148 We targeted metazoan (multicellular) organisms by PCR-amplifying part of the mitochondrial

149 cytochrome $c$ oxidase subunit I (COI) gene (313 bp for most metazoan species) using the primers

150 from Leray et al. (2013; mlCOIintF: GGWACWGGWTGAACWGTWTAYCCYCC,

151 jgHCO2198: TAIACYTCIGGRTGICCRAARAAYCA). COI is used as the 'DNA barcode' for

152 metazoans, and benefits from the Barcode of Life Database (BOLD) containing millions of 
153 reference COI DNA sequences for over 200,000 animal species (Hebert et al. 2003;

154 Ratnasingham \& Hebert 2007).

155 Metabarcoding libraries were prepared for sequencing as per Clarke et al. (2017). Specifically,

156 PCR amplifications were performed in two rounds, the first to amplify the target COI gene and

157 add sample-specific 6 bp multiplex-identifier (MID) tags (forward and reverse primer) and

158 Illumina sequencing primers, the second to add sequencing adapters and additional 8 bp MIDs.

159 Using two rounds of tagging reduces the chance of sequencing artefacts such as tag-jumping

160 leading to false-positives, as reads must include two pairs of unique MID tags to be assigned to a

161 given sample. The first round was the touchdown protocol as per Leray et al. (2013), namely 95

$162{ }^{\circ} \mathrm{C}$ for $10 \mathrm{~min}$, a 16 cycle touchdown phase $\left(62{ }^{\circ} \mathrm{C}-1{ }^{\circ} \mathrm{C}\right.$ per cycle), followed by 25 cycles with

163 an annealing temperature of $46^{\circ} \mathrm{C}$ (total of 41 cycles), and a final extension at $72{ }^{\circ} \mathrm{C}$ for $5 \mathrm{~min}$.

164 Although using a single low annealing temperature (e.g., $46^{\circ} \mathrm{C}$ ) rather than the touchdown

165 protocol can increase the number of species detected, this is biased towards increased detection

166 of non-metazoan (non-target) taxa (Clarke et al. 2017) and may be particularly problematic for

167 eDNA (Collins et al. 2019; Suter et al. 2020). We chose the touchdown protocol for this study to

168 maximise the number of metazoan reads per sample. Each reaction mix contained $0.5 \mu \mathrm{M}$ each

169 of forward and reverse primer, $2 \mu \mathrm{g}$ BSA, AmpliTaq Gold ${ }^{\mathrm{TM}} 360$ Master Mix in $1 \mathrm{x}$ reaction

170 buffer (Life Technologies, Melbourne, Australia), and $1 \mu \mathrm{L}$ DNA extract (undiluted) in a total

171 reaction volume of $10 \mu \mathrm{L}$. PCR products were diluted 1:10 and Illumina sequencing adapters

172 were added in a second round of PCR $\left(10\right.$ cycles with an annealing temperature of $\left.55^{\circ} \mathrm{C}\right)$ using

173 the same conditions as the first round, except primer concentrations were reduced to $0.1 \mu \mathrm{M}$

174 each. Products from each round of PCR were separated by electrophoresis and visualized on 2\%

175 agarose gels. Equal volumes of second round PCR products were pooled then purified using 
176 Agencourt AMPure XP beads (Beckman Coulter, Brea, CA, USA) and the size distribution and

177 concentration of the library assessed on a 2100 Bioanalyzer (Agilent Technologies, Santa Clara,

$178 \mathrm{CA}, \mathrm{USA}$ ). The pool was diluted to $2 \mathrm{nM}$ and paired-end reads generated on a MiSeq (Illumina,

179 San Diego, CA, USA) with the MiSeq Reagent Kit v2 (2 x 250 bp).

180

181 Bioinformatics

182 Our approach follows that in Suter et al. (2020). In brief, the MiSeq used the 8 bp MIDs to assign

183 sequences to sample-specific FASTQ files (available in the NCBI database under BioProject:

184 PRJNA720767). Paired reads were merged using USEARCH v10.0.240 (Edgar 2010). Only

185 reads with exact matches to first round $6 \mathrm{bp}$ MID tags and COI primer sequences (identified with

186 the R package 'ShortRead', Morgan et al. 2009; R Core Team 2017) were kept, as non-exact

187 matches are more likely to contain sequencing errors in the remainder of the sequence. These

188 processed sequences were then pooled and dereplicated using the USEARCH command

189 "fastx_uniques". The USEARCH command "unoise3" was used to remove sequencing errors

190 and chimaeras and create a list of unique zOTU (zero-radius operational taxonomic unit)

191 sequences with a minimum abundance of 8 reads. A zOTU table, with reads for individual

192 samples assigned to unique zOTUs, was created using the USEARCH command "otutab".

193 We used the 'blastn' command (Madden 2013) to search the zOTU sequences against the NCBI

194 nucleotide database (settings: -num_descriptions 50 -num_alignments 50 -num_threads 8 -

195 perc_identity 80; excluding environmental samples, metagenomes and unidentified organisms

196 using the command -negative_seqidlist). We imported these blastn results into MEGAN to

197 assign taxonomy (Huson et al. 2016; LCA parameters "min score": 300; "top percent": 5; "min

198 support": 1). zOTUs that were assigned to contaminant species were removed (only Homo 
199

200

201

202

203

204

205

206

207

208

209

210

211

212

213

214

215

216

217

218

219

220

221

sapiens in this dataset). zOTU assignments to metazoan taxa were manually curated, as LCA

parameters (e.g., "min score": 300) can result in zOTUs being assigned to species- or genus-level

despite low pairwise sequence identity (e.g., $<90 \%$ ). zOTU sequences with pairwise sequence identity $<90 \%$ were re-assigned to order level where necessary. The presence of additional metazoan species within zOTUs that were only resolved to a high taxonomic level was investigated by aligning all metazoan zOTU sequences with MUSCLE (Edgar 2004) and creating a consensus neighbour-joining phylogenetic tree using Geneious version 8.1.7 (https://www.geneious.com, Fig. S1). zOTU sequences that were only resolved to a high taxonomic level (e.g., kingdom, phylum, class or order) that formed a closely related ( $>97 \%$ identity) monophyletic group of at least two sequences resembling a species were renamed to e.g. "Metazoa sp. A". These sequences were also searched against all barcode records in the online Barcode of Life Database (BOLD, Ratnasingham \& Hebert 2007) Identification System to check if the taxonomy could be resolved to a lower level. Metazoan zOTU sequences that were not closely related to any other sequence, and with $<85 \%$ identity to a known species, were not included in the species-level analysis.

Three of the 50 most abundant zOTUs not assigned taxonomy using the NCBI database had matches with $80 \%$ pairwise identity to metazoan taxa in BOLD (Cyclopoida sp.) that formed a monophyletic group and were assigned to phylum level; three matched non-metazoan taxa; the remaining 44 zOTUs could not be classified. Given the low proportion of zOTUs not assigned using NCBI that were assigned taxonomy with BOLD, and the need for time-consuming manual curation of BOLD search results, we did not search the remaining unclassified zOTU sequences against BOLD. 


\section{Statistical analysis}

223 The metazoan species table was used for all alpha- and beta-diversity analyses. We examined

224 species richness (alpha-diversity) for each sample type with rarefaction curves generated using

225 the 'iNEXT' R package (Hsieh et al., 2016), and tested for differences in number of species

226 detected between sediment core sections, or eDNA and the uppermost (surface) core section,

227 using one-way ANOVA and a paired $t$-test, respectively, in R. We tested whether taxa from each

228 phylum were more prevalent in water or sediment samples by fitting a binomial generalised

229 linear model to the presence-absence data with terms for species and sample type (but no

230 interaction term). The species term allows the frequency of occurrence to differ for each species

231 within the taxonomic group, and the sample type term allows an additive effect of sample type

232 that applies equally to all species within the group. We tested the significance of the sample type

233 term using a likelihood ratio test, with a Bonferroni-corrected $p$-value based on the number of

234 test phyla (12).

235 The most appropriate community dissimilarity measure should yield reproducible results for

236 replicate samples. Therefore, we tested whether replicate water eDNA samples were more

237 similar based on presence-absence data or taking relative sequence abundance into account

238 (binary Jaccard vs. Bray-Curtis dissimilarity) using the Adonis method (Anderson 2001)

239 (compare_categories.py, 999 permutations) in QIIME v1.8.0 (Caporaso et al. 2010)

240 (beta_diversity_through_plots.py) based on a rarefied metazoan species table (1000 reads). The

241 same method was used to explore differences in sediment and water eDNA community

242 composition using binary Jaccard distance. The analysis was repeated using only water eDNA

243 and surface sediment samples from sites where sufficient data ( $>1000$ metazoan reads) was

244 available for both sample types (paired sites). The Linear Discriminant Analysis (LDA) Effect 
245 Size (LEfSe, Segata et al. 2011) method was used with default settings (LDA threshold $=2.0, \alpha$ $246=0.05)$ to highlight taxa that showed different abundances between sediment and water eDNA 247 samples at these paired sites.

248 Correlations between environmental variables (depth, distance to open ocean) and water eDNA 249 community composition were explored using the envfit function in the R package 'vegan'

250 (Oksanen et al. 2019). Depth and distance to open ocean were considered gross measures, 251 serving as proxies for finer scale environmental variables such as light level, current speed, 252 propagule sources, freshwater influence, etc., that are most likely to determine faunal 253 distributions. In the absence of data for these finer scale environmental measures, these simple 254 proxies allow us to begin testing for patterns in the data.

\section{In silico PCR}

257 Given we use a single COI marker to generate our dataset, it is unlikely to provide a 258 comprehensive survey of the benthic community. We used in silico PCR implemented through the ECOPCR program (Ficetola et al. 2010, see Supplemental Information) to inform metabarcoding marker choice for future, potentially multi-marker, eDNA studies of Antarctic

261 benthic communities. Specifically, we explored taxonomic coverage, resolving power and 262 suitability for several metabarcodes targeting mitochondrial COI and 16S genes as well as the 263 nuclear 18S rRNA gene for taxonomic groups under-represented in our COI data (benthic 264 arthropods) and other diverse Antarctic benthic metazoan taxa (annelids and molluscs). Further 265 details are provided in Supplemental Information. 


\section{Results}

\section{Sediment vs. water eDNA}

270 Metazoan reads

271 COI metabarcoding of the 80 samples (including 35 water eDNA, 42 sediment and three field or

272 lab negative controls) yielded 688,946 unique sequences prior to denoising, and a total of 5.45

273 million paired-end reads after filtering and quality control, representing 3950 zero-radius OTUS

274 (zOTUs). $518 \mathrm{zOTUs}$ and 2.163 million reads were assigned to a total of 99 metazoan taxa

275 representing 12 phyla. Approximately 40\% of reads were assigned to 'Metazoa' for both

276 sediment and water eDNA samples (Figure 2). In contrast, almost half (49.5\%) of sediment reads

277 were not classified, but only 33\% were not classified for water eDNA samples. Lab and field

278 negative controls contained no metazoan zOTUs, except for one with 49 reads assigned to

279 Australian fur seal, likely to represent lab contamination. This species was not detected in any

280 other sample. Sediment samples yielded almost twice the total number of metazoan reads

281 compared to water eDNA samples (Figure 2), due to both the greater number of reads per sample

282 on average (sediment mean \pm SD: $80,800 \pm 58,400$, water eDNA: $58,700 \pm 55,000$ ) and the

283 greater number of sediment samples. Metazoan zOTU sequences that were not closely related to

284 any other sequence, and with $<85 \%$ identity to a known species, were removed $(n=39)$. The 99

285 metazoan taxa in the 'species' table included 479 zOTUs and 2.156 million reads. More than half

286 the metazoan zOTUS (286) and 43\% of reads (980,071 reads) were assigned to the copepod

287 Paralabidocera grandispina. These zOTUs could also represent $P$. antarctica, a closely related,

288 co-occurring species without a publicly available COI sequence. Eleven samples (five water and

289 six sediment eDNA) had less than 1000 metazoan reads and were excluded from further analysis. 
290 The remaining 66 samples showed a large range in the number of reads per sample (1456-

291 156,765, mean \pm SD: $32671 \pm 32842$ reads).

292

293 Species richness

294 Despite the low number of reads per sample compared to microbial studies, the number of

295 species detected per sample approached an asymptote with 1000 reads for both sediment and

296 water eDNA samples (Figure 3). For sediment samples, more metazoan taxa were detected in the

297 uppermost core sections, but this was not statistically significant $\left(F_{4,31}=1.63, P=0.19\right.$, Figure 3$)$.

298 For the eight sectioned cores, more than half of all taxa detected in each were typically present in

299 the uppermost core section (mean \pm SD \% in uppermost section: $67 \pm 14 \%$ ). Combining the

300 uppermost core section with either the second uppermost or bottom core section increased the

301 proportion to approximately $80 \%$ of taxa in each core. Similar numbers of taxa were detected in

302 water eDNA samples and the top section of sediment cores at sites where both were collected

303 (paired $t$-test, $t=0.45$, d.f. $=7, P=0.67$, Figure 3 ).

304

305 Community composition

306 PERMANOVA showed replicate water eDNA samples (six sites, four locations, $\mathrm{n}=12$ ) were

307 grouped according to site and location with binary Jaccard distance $\left(F_{5,6}=2.91, R^{2}=0.71\right.$,

$308 P<0.001$, Figure S2), but comparatively weakly for Bray-Curtis dissimilarity based on both

309 rarefied sequence counts $\left(F_{5,6}=1.83, R^{2}=0.60, P=0.037\right)$ and square-root transformed and rarefied

310 sequence counts $\left(F_{5,6}=2.30, R^{2}=0.66, P=0.006\right)$. All subsequent beta-diversity analyses were

311 based on binary Jaccard distance as it yielded more reproducible community profiles for

312 replicate samples. For three sites, the majority of metazoan taxa were detected in both replicates

Peer] reviewing PDF | (2021:04:59953:2:0:NEW 14 Sep 2021) 
313 (61-68\% based on the non-rarefied data), but only $27-38 \%$ of metazoans were detected in both

314 replicates at the other three sites. More taxa were always detected in the replicate with greater 315 sequencing depth.

316 Almost half of all metazoan species were detected in both sediment and water eDNA samples 317 (47/99, 47.5\%, Figure 4). 22 and 30 species were detected exclusively with sediment or water 318 eDNA, respectively. Taxa from four phyla were significantly more prevalent in either water 319 (Echinodermata, Cnidaria and Chordata) or sediment samples (Nematoda, $P<0.001$ for each 320 phylum). For example, the frequency of occurrence for all echinoderm and chordate taxa, 321 including the Antarctic ploughfish Gymnodraco acuticeps, was higher in water than sediment 322 samples, whereas 12/15 nematode taxa had a higher frequency of occurrence in sediment.

323 Metazoan communities from water and sediment eDNA samples were significantly different $324\left(F_{1,64}=9.59, R^{2}=0.130, P<0.001\right.$, Figure $\left.5 \mathrm{~A}\right)$. This analysis includes water samples from hard325 bottom sites, where sediment was not sampled, but are likely to support benthic communities that 326 are distinct from soft-bottom sites (Kirkwood \& Burton 1988). Similarly, water eDNA samples are likely to be most similar to the uppermost $(0-2 \mathrm{~cm})$ sediment samples rather than deeper core sections. However, repeating the analysis with only water eDNA and the uppermost sediment samples from sites where sufficient data ( $>1000$ metazoan reads) was available for both sample types (paired sites) demonstrated that the two sample types still yielded distinct communities $\left(F_{1,12}=2.16, R^{2}=0.152, P=0.009\right.$, Figure $\left.5 \mathrm{~B}\right)$. Based on the sediment and water eDNA samples

332 from sites where both were collected, 10 taxa were significantly more abundant in either water 333 eDNA (9) or sediment (1, Figure 6). Taxa that showed higher relative abundance in water eDNA 334 samples included the Antarctic sea urchin Sterechinus neumayeri, an unidentified arthropod, a 335 hesionid polychaete, and the epibenthic polychaete Polynoidae sp. 212 RG-2014 (Figure 6). The 
336 one taxon enriched in sediment samples was the abundant sea-ice associated copepod

337 Paralabidocera grandispina/antarctica (Figure 6).

338

Environmental influence on water eDNA community composition

340 An nMDS of water eDNA samples showed nearby sites often yielded similar community

341 profiles, as sites within a location were often similar (e.g., two sites near Bandits, and two sites

342 within Shirokaya Bay), as well as sites from nearby locations (e.g., Hawker Channel and

343 Warriner Channel, Figure 7). However, some locations showed high site-to-site heterogeneity in

344 community composition, e.g., within Ellis Fjord and within Weddell Arm. Different

345 communities are expected between Ellis Fjord sites, as they are spread over several kilometres

346 (Figure 1) and both environmental conditions and habitat type vary over the length of the fjord

347 (Kirkwood \& Burton 1988). Similarly, the two Weddell Arm sites represented distinct habitat

348 types (predominantly hard vs. soft bottom) with different communities. Distance to open ocean

349 explained $17.3 \%$ of variance in water eDNA communities but was not significant at the 0.05

350 level $\left(R^{2}=0.173, P=0.072\right.$, Figure 7$)$. There was no evidence that depth was correlated with water

351 eDNA community composition $\left(R^{2}=0.076, P=0.35\right)$.

352

353 In silico PCR

354 The Leray COI primers used in our study (Leray et al. 2013) provided 88\% species-level

355 coverage for benthic arthropods in silico (Table 1), with a 4 and 9\% increase in coverage using 356 the modified forward primer proposed by Rennstam Rubbmark et al. (2018) and Wangensteen et 357 al. (2018), respectively. The increased coverage provided by the modified COI primers points to 
358 the potential to design new COI primers to better target benthic arthropods. All three COI 359 primers resolved $97 \%$ of arthropod species 'amplified'.

360 18S primers targeting the V9 region for Peracarida (including amphipods, isopods, tanaids and 361 cumaceans, Taberlet et al. 2018) resolved the lowest proportion of species (79\%), and were only 362 able to resolve many taxa at the family or order-level. In contrast, eukaryote $18 \mathrm{~S}$ primers 363 targeting the V4 region (Piredda et al. 2017; Stoeck et al. 2010) provided similar taxonomic 364 coverage to other markers (92\%), and near-perfect species-level resolution (99\%). However, the 365 length and size variation of the amplicon (mean \pm SD: $580 \pm 88 \mathrm{bp}$, range: $372-965 \mathrm{bp}$ ) make it 366 difficult to sequence with most commonly used sequencing platforms (e.g., Illumina MiSeq), and 367 is likely to introduce a PCR-amplification and sequencing bias against taxa with longer

368 amplicons. 18S rRNA primer-binding sites are also well-conserved across eukaryotic taxa, 369 increasing the likelihood of amplifying non-metazoan eukaryotes.

370 The two longer $16 \mathrm{~S}$ metabarcodes resolved a similar proportion of species as the COI

371 metabarcodes ( $97 \%$, Table 1 ), with the shorter $16 \mathrm{~S}$ metabarcode ( $\sim 57 \mathrm{bp}$ ) only resolving $89 \%$ of 372 species. Comparatively low species coverage (76\%) for the Ins_16S primers (Clarke et al. 2014) 373 suggest these primers should be redesigned prior to use with benthic arthropod communities.

374 In silico analyses for two other major benthic taxonomic groups (annelids and molluscs) yielded 375 similar results (Table S3 and S4). Namely, the modified COI proposed by Rennstam Rubbmark 376 et al. (2018) and Wangensteen et al. (2018) increased coverage by 3-4 and 9-11\% compared to 377 the Leray primers for annelids and molluses, respectively. COI primers provided $>92 \%$ species378 level resolution for both groups, whereas resolution was only $22-74 \%$ for $18 \mathrm{~S}$ (both V4 and V9) 379 and 16S rRNA markers. The 18S V9 marker tested (Euka03) also had poor taxonomic coverage 380 for both annelids and molluses ( 21 and $25 \%$, respectively). Both $16 \mathrm{~S}$ markers tested were short 
381 (mean length: 63-64 bp), and primers targeting longer variable regions of the mitochondrial 16S

382 gene may have better resolving power.

383

384 Discussion

385 In this study, we found that water and sediment eDNA samples yielded similar proportions of 386 reads assigned to metazoans and similar metazoan species richness, but differed in their

387 community composition. Our results support the findings of previous eDNA studies that the

388 choice of sample type (e.g., sediment vs. water) needs to be carefully considered in the context of

389 the research or monitoring question (Antich et al. 2020; Brandt et al. 2021; Holman et al. 2019;

390 Koziol et al. 2019). For example, is the aim to monitor change in a particular (pelagic or benthic)

391 habitat, or detect specific target taxa, or generate a comprehensive biodiversity assessment for a

392 site? Although more than half the species in this study were detected in both sediment and water

393 eDNA, significantly different metazoan communities were detected in the two sample types at

394 sites where both were collected, highlighting the complementarity of sediment and water eDNA

395 samples and the utility of collecting both when assessing biodiversity in nearshore benthic

396 environments. The fact that many species were detected in both water and sediment is

397 unsurprising, as some of these species would be found in both sediment and hard-bottom habitats

398 (e.g. polynoids, asteroids, holothurians). In addition, Antarctic benthic ecosystems are often a

399 mosaic of hard and soft habitats, with patch sizes ranging from very small (sub metre) to much

400 larger patches (Stark et al. 2003). Even where habitat is primarily hard bottom, patches of soft

401 sediments can be found between boulders and on small terraces, and hard surfaces are often

402 overlain by a thin layer of fine sediments due to very low current velocities.

403

Peer] reviewing PDF | (2021:04:59953:2:0:NEW 14 Sep 2021) 


\section{Influence of sample type on taxa detected}

405 Quantitative comparisons of species richness detected in very different sample types are

406 challenging. However, we found similar numbers of species were detected with both sediment

407 and water eDNA, but the taxa detected in each sample type reflected their respective habitat

408 preferences. Nematode species were more prevalent in sediment, and echinoderms, in particular

409 holothuroids, in water eDNA, likely attributable to habitat preference as infauna and epifauna,

410 respectively, as well as the potential for broadcast spawning of echinoderm gametes. Similar

411 effects of habitat on the taxa detected have been observed in comparisons of sediment and water

412 eDNA from temperate locations (Holman et al. 2019; Koziol et al. 2019). Holman et al. (2019)

413 found more species were detected in sediment than water eDNA samples from coastal sites in the

414 United Kingdom. Both studies filtered similar volumes of water per sample, but Holman et al.

415 (2019) extracted DNA from $10 \mathrm{~g}$ sediment, compared to $250 \mathrm{mg}$ in this study, which could lead

416 to the greater diversity in sediment samples observed in their study. Methods to concentrate

417 metazoan taxa from larger volumes of either water (e.g., Suter et al. 2020) or sediment (e.g.,

418 Brannock \& Halanych 2015) will also increase the proportion of metazoan reads and number of

419 metazoan species detected, albeit with an increase in the time required to process each sample.

420 Our decision to extract DNA from $250 \mathrm{mg}$ sediment was driven by a practical consideration to

421 use the same extraction kit for water and sediment samples (Hermans et al. 2018). We found

422 pooling data from the uppermost core section with other individual core sections only provided

423 an increase from $67 \%$ to approximately $80 \%$ of taxa in each core, suggesting we were not

424 missing substantial metazoan diversity by processing $250 \mathrm{mg}$ samples. Similarly, given Antarctic

425 sediment samples are difficult to obtain, they are also often in demand for multiple types of

426 analyses and therefore the use of smaller sample sizes is often preferred. Extracting DNA from 
427 small-volume sub-samples may be more realistic in such circumstances. Optimal sediment

428 sampling design, sample size and/or sample processing for eDNA analysis is worthy of further

429 investigation.

430 Environmental DNA signals are more homogeneous in the water column compared to soil,

431 sediment or settlement plates (Andersen et al. 2012; Koziol et al. 2019; Thomsen et al. 2012),

432 and water eDNA may provide a simple means to assess site-wide biodiversity. For example,

433 Koziol et al. (2019) found less variation between replicate water eDNA samples compared to

434 sediment or settlement plate replicates. However, recent studies show that marine eDNA signals

435 reflect local communities, with minimal transfer of eDNA between three distinct habitat types

436 separated by less than $5 \mathrm{~km}$ subject to tidal and long-shore currents, and less than $10 \mathrm{~m}$ in a

437 stratified water column (Jeunen et al. 2019; Jeunen et al. 2020). East Antarctic soft-bottom

438 communities can show significant small-scale patchiness (Stark et al. 2003). Such heterogeneity

439 needs to be considered when choosing whether to process one large or many small sediment

440 DNA samples, (e.g., one $10 \mathrm{~g}$ sample or five $250 \mathrm{mg}$ samples), or combining multiple small

441 samples into a larger composite sample.

442

443 Reconciling DNA-based and morphology-based approaches

444 Reconciling a DNA-based approach to biodiversity assessment and monitoring with traditional

445 morphology-based approaches can be difficult (e.g., Deagle et al. 2018). Environmental DNA

446 approaches can detect organisms from the full size spectrum, including macro-organisms. For

447 example, we detected Antarctic ploughfish (Gymnodraco acuticeps) in one water eDNA sample.

448 This can complicate comparison with traditional morphology-based approaches that would

449 typically focus on a particular size fraction (e.g., meiofauna) or habitat (e.g., epifauna versus 
450 infauna). Higher diversity often reported for DNA-based approaches could reflect sampling a 451 broader pool of species. Similarly, environmental DNA cannot differentiate between planktonic 452 (and potentially temporary resident) and benthic organisms (usually a permanent resident of a 453 site). For example, the polychaete Polynoidae sp. 212 RG-2014 was first described from West 454 Antarctic meroplankton communities (Gallego et al. 2014), and was significantly more abundant 455 in water eDNA compared to sediment samples in this study (Figure 6). Lastly, a benefit, but also 456 a drawback, of a DNA-based approach is that, although DNA can potentially identify juvenile 457 and larval life stages that may be impossible to identify based on morphology, DNA does not 458 provide demographic information, and cannot differentiate between larval, juvenile and adult life 459 stages. It is possible that DNA-based approaches may detect gametes or eggs of a species at a 460 site where adults are not present. However, such sensitivity could be valuable for the early 461 detection of non-indigenous and invasive species.

462 Many arthropod taxa present in the Vestfold Hills nearshore benthos were not detected in this 463 study, suggesting that additional markers are necessary for a comprehensive survey of the 464 metazoan community. Taxa not detected, but known to be present in nearshore benthic 465 communities in the Vestfold Hills region (Everitt et al. 1980), included ostracods, gammarid 466 amphipods and isopods. Similarly, only a single zOTU was assigned to an amphipod, typically a 467 common and diverse group in this region, where they can comprise over $80 \%$ of the macrofauna 468 (infauna $>0.5 \mathrm{~mm}$, Stark et al. 2014b; Stark et al. 2003). The failure to detect these taxa could be 469 due to either primer bias or the lack of publicly available reference COI sequences. Available 470 ostracod, isopod and gammarid amphipod mitochondrial genomes contain 1-4 mismatches to the 471 forward Leray primer, and 0-1 mismatches in the reverse, raising the possibility of primer bias. 
472 Crustacean and/or taxon-specific COI or 16S ribosomal RNA primers (e.g., Stat et al. 2017) and

473 continued development of reference databases may be necessary to properly assess regional

474 diversity. However, no COI sequences are available for several of the most common isopod,

475 ostracod and tanaids that occur at the site, even for congeneric species (Austrosignum,

476 Philomedes, Scleroconcha and Nototanais sp.), and could explain the high proportion of reads

477 not classified in the sediment. Similarly, annelids were the most diverse phylum (24 distinct

478 taxa), including 11 of the 16 taxa with the highest mean relative abundances (Figure 6), but only

479 three were resolved to genus or species level. These taxa should be the focus of new DNA

480 barcoding campaigns to improve their coverage in reference DNA sequence databases like

481 BOLD. Until additional reference sequence data is available, these taxa can only be detected and

482 identified to species or genus-level by morphology-based approaches, further emphasising the

483 need for complementary approaches (e.g., Sinniger et al. 2016).

484 The ideal eDNA metabarcoding marker is universal for the taxa of interest (i.e., no major

485 taxonomic primer bias) with sufficient sequence divergence to resolve species (Clarke et al.

486 2014), whilst being amenable to sequencing on widely used platforms such as the Illumina

487 MiSeq. The three most commonly used metazoan metabarcoding markers target the nuclear 18S

488 rRNA gene, or the mitochondrial COI or 16S rRNA genes. Reference sequence data should also

489 be available for the marker of interest. Of the 64 benthic arthropod species recorded near the

490 Davis and Casey East Antarctic stations, approximately half have sequence data available for

491 COI or $18 \mathrm{~S}$ at the genus level (31 and 29 species, respectively), but only a third have $16 \mathrm{~S}$ data

492 (22 species). Species-level data for these benthic arthropods is only 7-11 species per marker.

493 However, the lack of reference sequences for any marker can be overcome with a dedicated

494 sequencing campaign, or an OTU-based approach to taxonomy (e.g., Ji et al. 2013). Although an 
495 OTU-based approach is possible in the absence of reference sequence data, species-level

496 identifications are by far the most desirable for biodiversity monitoring. Researchers wanting to

497 integrate DNA-based data with data obtained through other methods like morphology-based

498 identification should target markers that provide species-level resolution, such as COI, 16S

499 regions $>100 \mathrm{bp}$ in length, and/or universal 18S V4 markers (Table 1).

500

501 Metabarcoding markers should also targeted to the taxa of interest, with the amplification of non-

502 target reads kept to a minimum. We found only $\sim 40 \%$ of reads were assigned to metazoa using

503 the Leray COI marker, and a significant proportion of reads were lost to non-target taxa (both

504 non-metazoan and unclassified). Low proportions of metazoan reads could be addressed by

505 concentrating metazoan taxa within the water or sediment sample by filtration or elutriation, for

506 example (e.g., Brannock \& Halanych 2015; Suter et al. 2020).

507 Comprehensive benthic metazoan biodiversity surveys may require re-designing the Leray COI

508 primers to better target benthic arthropods and molluscs, or testing primers targeting the variable

509 regions of the nuclear $18 \mathrm{~S}$ or mitochondrial 16S ribosomal RNA gene. Although designing and

510 testing new primers is beyond the scope of the current study, further investigations could

511 include: 1) in silico PCR to test taxonomic resolution in closely related species (e.g., congeneric

512 species), and to test for non-specific amplification of other common environmental species or

513 contaminants (bacteria, human DNA); 2) testing primers on DNA extracts from individual

514 specimens to optimise PCR conditions and confirm a PCR product of the expected size is

515 amplified with no non-specific amplification; 3) a small-scale sequencing run testing primers on

516 a mix of DNA extracts from benthic arthropods and a small number of environmental samples. 


\section{Conclusions}

519 We recommend future DNA-based biodiversity assessments for Antarctic nearshore

520 environments include water eDNA along with sediment sampling if suitable for the research or

521 monitoring question, given similar numbers of species were detected in both water and sediment

522 samples, the comparative ease of collecting water samples, and the versatility of sampling both

523 hard- and soft-bottom sites. DNA in sediments may be derived from dead tissue, such as

524 seaweed wrack, that originated from spatially or temporally distant sites, particularly given the

525 temperature in Antarctic waters. Future eDNA studies testing the environmental drivers of

526 eDNA community composition should collect data for environmental variables known to be

527 important in structuring benthic communities (e.g., sediment grain size, proportion of hard versus

528 soft habitat, etc.) in conjunction with sample collection. We found that combining data from

529 replicate water eDNA samples increased the number of taxa detected at each site. As well as

530 being essential for rigorous statistical analysis, including replicates is probably a more efficient

531 method for improving metazoan biodiversity detection than increasing sequencing depth for this

532 marker, as the number of species detected per sample approached an asymptote with 1000

533 metazoan reads, and only $\sim 40 \%$ of reads were assigned to metazoa.

534 Non-invasive, "capture-free" approaches like eDNA also raise the question: how do we know an

535 organism detected with eDNA is really there? (Darling 2020). Although several recent studies

536 suggest that marine eDNA signals are a snapshot of the local community (Jeunen et al. 2019;

537 Jeunen et al. 2020; Suter et al. 2020), the fate and transport of eDNA in Antarctic benthic

538 environments poses unique challenges. Year-round low temperatures potentially extend the

539 lifespan of eDNA. However, DNA degradation rate is not solely a physical property, as both the

540 water column and sediment contain active microbial communities. Low current velocities in 
541 many coastal Antarctic sites reduce the chance that DNA will be introduced from distant sites,

542 but could increase residence time beyond that of the parent organism. For example, the higher

543 relative abundance of the sea-ice associated copepod Paralabidocera grandispina/antarctica in

544 sediment compared to water eDNA is likely to reflect accumulation of eggs in the sediment

545 (Swadling et al. 2004), demonstrating that DNA-based detections do not necessarily reflect

546 species active within the sample. An understanding of the spatial distribution of eDNA in

547 Antarctic benthic ecosystems, from a few metres to several kilometres, should be paired with

548 careful cataloguing of the actual biodiversity present using other methods. Knowledge of spatial

549 and/or temporal eDNA variation could then be combined with site occupancy-detection models

550 to accurately infer species distributions (Chen \& Ficetola 2019).

551

552 Acknowledgements

553 James Marthick (Menzies Institute for Medical Research, University of Tasmania) facilitated use

554 of the MiSeq Genome Sequencer. Helen Achurch (AAD) helped adapt the map in Figure 1. Ben

555 Raymond (AAD) provided advice on statistical analysis.

556

557 References

558

559

560

561

562

563

564

565

566
Andersen K, Bird KL, Rasmussen M, Haile J, Breuning-Madsen H, KjÆR KH, Orlando L, Gilbert MTP, and Willerslev E. 2012. Meta-barcoding of 'dirt' DNA from soil reflects vertebrate biodiversity. Molecular Ecology 21:1966-1979. DOI: 10.1111/j.1365294X.2011.05261.x

Anderson MJ. 2001. A new method for non-parametric multivariate analysis of variance. Austral Ecology 26:32-46. DOI: 10.1111/j.1442-9993.2001.01070.pp.x

Antich A, Palacin C, Cebrian E, Golo R, Wangensteen OS, and Turon X. 2020. Marine biomonitoring with eDNA: Can metabarcoding of water samples cut it as a tool for surveying benthic communities? Mol Ecol. DOI: 10.1111/mec.15641 
567

568

569

570

571

572

573

574

575

576

577

578

579

580

581

582

583

584

585

586

587

588

589

590

591

592

593

594

595

596

597

598

599

600

601

602

603

604

605

606

607

608

609

610

611
Aronson RB, Thatje S, Clarke A, Peck LS, Blake DB, Wilga CD, and Seibel BA. 2007. Climate change and invasibility of the Antarctic benthos. Annual Review of Ecology, Evolution, and Systematics 38:129-154. DOI: 10.1146/annurev.ecolsys.38.091206.095525

Barnes DKA, and Peck LS. 2008. Vulnerability of Antarctic shelf biodiversity to predicted regional warming. Climate Research 37:149-163. DOI: 10.3354/cr00760

Brandt MI, Pradillon F, Trouche B, Henry N, Liautard-Haag C, Cambon-Bonavita MA, CueffGauchard V, Wincker P, Belser C, Poulain J, Arnaud-Haond S, and Zeppilli D. 2021. Evaluating sediment and water sampling methods for the estimation of deep-sea biodiversity using environmental DNA. Sci Rep 11:7856. DOI: 10.1038/s41598-02186396-8

Brannock PM, and Halanych KM. 2015. Meiofaunal community analysis by high-throughput sequencing: comparison of extraction, quality filtering, and clustering methods. Mar Genomics 23:67-75. DOI: 10.1016/j.margen.2015.05.007

Brannock PM, Learman DR, Mahon AR, Santos SR, and Halanych KM. 2018. Meiobenthic community composition and biodiversity along a $5500 \mathrm{~km}$ transect of Western Antarctica: a metabarcoding analysis. Marine Ecology Progress Series 603:47-60. DOI: $10.3354 /$ meps 12717

Brooks ST, Jabour J, van den Hoff J, and Bergstrom DM. 2019. Our footprint on Antarctica competes with nature for rare ice-free land. Nature Sustainability 2:185-190. DOI: 10.1038/s41893-019-0237-y

Caporaso JG, Kuczynski J, Stombaugh J, Bittinger K, Bushman FD, Costello EK, Fierer N, Peña AG, Goodrich JK, Gordon JI, Huttley GA, Kelley ST, Knights D, Koenig JE, Ley RE, Lozupone CA, McDonald D, Muegge BD, Pirrung M, Reeder J, Sevinsky JR, Turnbaugh PJ, Walters WA, Widmann J, Yatsunenko T, Zaneveld J, and Knight R. 2010. QIIME allows analysis of high-throughput community sequencing data. Nature Methods 7:335336. DOI: $10.1038 /$ nmeth0510-335

Chen W, and Ficetola GF. 2019. Conditionally autoregressive models improve occupancy analyses of autocorrelated data: An example with environmental DNA. Molecular Ecology Resources 19:163-175. DOI: https://doi.org/10.1111/1755-0998.12949

Chown SL, Huiskes AHL, Gremmen NJM, Lee JE, Terauds A, Crosbie K, Frenot Y, Hughes KA, Imura S, Kiefer K, Lebouvier M, Raymond B, Tsujimoto M, Ware C, Van de Vijver B, and Bergstrom DM. 2012. Continent-wide risk assessment for the establishment of nonindigenous species in Antarctica. Proceedings of the National Academy of Sciences 109:4938. DOI: 10.1073/pnas.1119787109

Clark GF, Raymond B, Riddle MJ, Stark JS, and Johnston EL. 2015. Vulnerability of Antarctic shallow invertebrate-dominated ecosystems. Austral Ecology 40:482-491. DOI: 10.1111/aec. 12237

Clarke LJ, Beard JM, Swadling KM, and Deagle BE. 2017. Effect of marker choice and thermal cycling protocol on zooplankton DNA metabarcoding studies. Ecology and Evolution 7:873-883. DOI: 10.1002/ece3.2667

Clarke LJ, Soubrier J, Weyrich LS, and Cooper A. 2014. Environmental metabarcodes for insects: in silico PCR reveals potential for taxonomic bias. Molecular Ecology Resources 14:1160-1170. DOI: 10.1111/1755-0998.12265

Collins RA, Bakker J, Wangensteen OS, Soto AZ, Corrigan L, Sims DW, Genner MJ, and Mariani S. 2019. Non-specific amplification compromises environmental DNA

Peer] reviewing PDF | (2021:04:59953:2:0:NEW 14 Sep 2021) 
612

613

614

615

616

617

618

619

620

621

622

623

624

625

626

627

628

629

630

631

632

633

634

635

636

637

638

639

640

641

642

643

644

645

646

647

648

649

650

651

652

653

654

655

656

metabarcoding with COI. Methods in Ecology and Evolution 10:1985-2001. DOI: 10.1111/2041-210X.13276

Darling JA. 2020. How to learn to stop worrying and love environmental DNA monitoring. Aquatic Ecosystem Health \& Management 22:440-451. DOI: 10.1080/14634988.2019.1682912

Deagle BE, Clarke LJ, Kitchener JA, Polanowski AM, and Davidson AT. 2018. Genetic monitoring of open ocean biodiversity: An evaluation of DNA metabarcoding for processing continuous plankton recorder samples. Molecular Ecology Resources 18:391406.

Edgar RC. 2004. MUSCLE: a multiple sequence alignment method with reduced time and space complexity. BMC Bioinformatics 5:113. DOI: 10.1186/1471-2105-5-113

Edgar RC. 2010. Search and clustering orders of magnitude faster than BLAST. Bioinformatics 26:2460-2461. DOI: 10.1093/bioinformatics/btq461

Everitt DA, Poore GCB, and Pickard J. 1980. Marine benthos from Davis Station, East Antarctica. Australian Journal of Marine and Freshwater Research 31:829-836.

Ficetola GF, Coissac E, Zundel S, Riaz T, Shehzad W, Bessière J, Taberlet P, and Pompanon F. 2010. An in silico approach for the evaluation of DNA barcodes. BMC Genomics 11:434. DOI: $10.1186 / 1471-2164-11-434$

Filgueiras VL, Campos LS, Lavrado HP, Frensel R, and Pollery RCG. 2007. Vertical distribution of macrobenthic infauna from the shallow sublittoral zone of Admiralty Bay, King George Island, Antarctica. Polar Biology 30:1439-1447. DOI: 10.1007/s00300-0070305-z

Fonseca VG, Sinniger F, Gaspar JM, Quince C, Creer S, Power DM, Peck LS, and Clark MS. 2017. Revealing higher than expected meiofaunal diversity in Antarctic sediments: a metabarcoding approach. Sci Rep 7:6094. DOI: 10.1038/s41598-017-06687-x

Gallego R, Lavery S, and Sewell MA. 2014. The meroplankton community of the oceanic Ross Sea during late summer. Antarctic Science 26:345-360. DOI: 10.1017/S0954102013000795

Halanych KM, and Mahon AR. 2018. Challenging dogma concerning biogeographic patterns of Antarctica and the Southern Ocean. Annual Review of Ecology, Evolution, and Systematics 49:355-378. DOI: 10.1146/annurev-ecolsys-121415032139

Hebert PDN, Cywinska A, Ball SL, and deWaard JR. 2003. Biological identifications through DNA barcodes. Proceedings of the Royal Society of London Series B: Biological Sciences 270:313-321. DOI: 10.1098/rspb.2002.2218

Hermans SM, Buckley HL, and Lear G. 2018. Optimal extraction methods for the simultaneous analysis of DNA from diverse organisms and sample types. Mol Ecol Resour 18:557-569. DOI: 10.1111/1755-0998.12762

Holman LE, de Bruyn M, Creer S, Carvalho G, Robidart J, and Rius M. 2019. Detection of introduced and resident marine species using environmental DNA metabarcoding of sediment and water. Sci Rep 9:11559. DOI: 10.1038/s41598-019-47899-7

Huson DH, Beier S, Flade I, Górska A, El-Hadidi M, Mitra S, Ruscheweyh H-J, and Tappu R. 2016. MEGAN community edition-interactive exploration and analysis of large-scale microbiome sequencing data. PLoS Computational Biology 12:e1004957.

Jeunen GJ, Knapp M, Spencer HG, Lamare MD, Taylor HR, Stat M, Bunce M, and Gemmell NJ. 2019. Environmental DNA (eDNA) metabarcoding reveals strong discrimination among

PeerJ reviewing PDF | (2021:04:59953:2:0:NEW 14 Sep 2021) 
657

658

659

660

661

662

663

664

665

666

667

668

669

670

671

672

673

674

675

676

677

678

679

680

681

682

683

684

685

686

687

688

689

690

691

692

693

694

695

696

697

698

699

700

701

diverse marine habitats connected by water movement. Molecular Ecology Resources 19:426-438. DOI: 10.1111/1755-0998.12982

Jeunen GJ, Lamare MD, Knapp M, Spencer HG, Taylor HR, Stat M, Bunce M, and Gemmell NJ. 2020. Water stratification in the marine biome restricts vertical environmental DNA (eDNA) signal dispersal. Environmental DNA 2:99-111. DOI: 10.1002/edn3.49

Ji Y, Ashton L, Pedley SM, Edwards DP, Tang Y, Nakamura A, Kitching R, Dolman PM, Woodcock P, Edwards FA, Larsen TH, Hsu WW, Benedick S, Hamer KC, Wilcove DS, Bruce C, Wang X, Levi T, Lott M, Emerson BC, and Yu DW. 2013. Reliable, verifiable and efficient monitoring of biodiversity via metabarcoding. Ecology Letters 16:12451257. DOI: 10.1111/ele.12162

Kaiser S, Brandão SN, Brix S, Barnes DKA, Bowden DA, Ingels J, Leese F, Schiaparelli S, Arango CP, Badhe R, Bax N, Blazewicz-Paszkowycz M, Brandt A, Brenke N, Catarino AI, David B, De Ridder C, Dubois P, Ellingsen KE, Glover AG, Griffiths HJ, Gutt J, Halanych KM, Havermans C, Held C, Janussen D, Lörz A-N, Pearce DA, Pierrat B, Riehl T, Rose A, Sands CJ, Soler-Membrives A, Schüller M, Strugnell JM, Vanreusel A, Veit-Köhler G, Wilson NG, and Yasuhara M. 2013. Patterns, processes and vulnerability of Southern Ocean benthos: a decadal leap in knowledge and understanding. Marine Biology 160:2295-2317. DOI: 10.1007/s00227-013-2232-6

Kirkwood JM, and Burton HR. 1988. Macrobenthic species assemblages in Ellis Fjord, Vestfold Hills, Antarctica. Marine Biology 97:445-457.

Koziol A, Stat M, Simpson T, Jarman S, DiBattista JD, Harvey ES, Marnane M, McDonald J, and Bunce M. 2019. Environmental DNA metabarcoding studies are critically affected by substrate selection. Mol Ecol Resour 19:366-376. DOI: 10.1111/1755-0998.12971

Leduc N, Lacoursière-Roussel A, Howland KL, Archambault P, Sevellec M, Normandeau E, Dispas A, Winkler G, McKindsey CW, and Simard N. 2019. Comparing eDNA metabarcoding and species collection for documenting Arctic metazoan biodiversity. Environmental DNA 1:342-358.

Leray M, Yang JY, Meyer CP, Mills SC, Agudelo N, Ranwez V, Boehm JT, and Machida RJ. 2013. A new versatile primer set targeting a short fragment of the mitochondrial COI region for metabarcoding metazoan diversity: application for characterizing coral reef fish gut contents. Frontiers in Zoology 10:34. DOI: 10.1186/1742-9994-10-34

Madden T. 2013. The BLAST sequence analysis tool. The NCBI Handbook. 2nd edition ed. Bethesda (MD): National Center for Biotechnology Information (US).

Morgan M, Anders S, Lawrence M, Aboyoun P, Pages H, and Gentleman R. 2009. ShortRead: a bioconductor package for input, quality assessment and exploration of high-throughput sequence data. Bioinformatics 25:2607-2608.

Oksanen J, Blanchet FG, Friendly M, Kindt R, Legendre P, McGlinn D, Minchin PR, O'Hara RB, Simpson GL, Solymos P, Stevens MHH, Szoecs E, and Wagner H. 2019. vegan: Community Ecology Package. R package version 2.5-6.

Piredda R, Tomasino MP, D'Erchia AM, Manzari C, Pesole G, Montresor M, Kooistra WH, Sarno D, and Zingone A. 2017. Diversity and temporal patterns of planktonic protist assemblages at a Mediterranean Long Term Ecological Research site. FEMS Microbiology Ecology 93:fiw200. DOI: 10.1093/femsec/fiw200

R Core Team. 2017. R: A language and environment for statistical computing. Vienna, Austria: R Foundation for Statistical Computing. 
702

703

704

705

706

707

708

709

710

711

712

713

714

715

716

717

718

719

720

721

722

723

724

725

726

727

728

729

730

731

732

733

734

735

736

737

738

739

740

741

742

743

744

745
Ratnasingham S, and Hebert PDN. 2007. BOLD: The Barcode of Life Data System (www.barcodinglife.org). Molecular Ecology Notes 7:355-364. DOI: 10.1111/j.14718286.2006.01678.x

Rennstam Rubbmark O, Sint D, Horngacher N, and Traugott M. 2018. A broadly applicable COI primer pair and an efficient single-tube amplicon library preparation protocol for metabarcoding. Ecol Evol 8:12335-12350. DOI: 10.1002/ece3.4520

Segata N, Izard J, Waldron L, Gevers D, Miropolsky L, Garrett WS, and Huttenhower C. 2011. Metagenomic biomarker discovery and explanation. Genome Biology 12:R60. DOI: 10.1186/gb-2011-12-6-r60

Sinniger F, Pawlowski J, Harii S, Gooday AJ, Yamamoto H, Chevaldonné P, Cedhagen T, Carvalho G, and Creer S. 2016. Worldwide analysis of sedimentary DNA reveals major gaps in taxonomic knowledge of deep-sea benthos. Frontiers in Marine Science 3. DOI: 10.3389/fmars.2016.00092

Smith J, O'Brien PE, Stark JS, Johnstone GJ, and Riddle MJ. 2015. Integrating multibeam sonar and underwater video data to map benthic habitats in an East Antarctic nearshore environment. Estuarine, Coastal and Shelf Science 164:520-536. DOI: 10.1016/j.ecss.2015.07.036

Stark JS, Kim SL, and Oliver JS. 2014a. Anthropogenic disturbance and biodiversity of marine benthic communities in Antarctica: a regional comparison. PLoS One 9:e98802. DOI: 10.1371/journal.pone.0098802

Stark JS, Kim SL, and Oliver JS. 2014b. Anthropogenic disturbance and biodiversity of marine benthic communities in Antarctica: a regional comparison. PLoS One 9:e98802-e98802. DOI: 10.1371/journal.pone.0098802

Stark JS, Riddle MJ, and Simpson RD. 2003. Human impacts in soft-sediment assemblages at Casey Station, East Antarctica: Spatial variation, taxonomic resolution and data transformation. Austral Ecology 28:287-304.

Stat M, Huggett MJ, Bernasconi R, DiBattista JD, Berry TE, Newman SJ, Harvey ES, and Bunce M. 2017. Ecosystem biomonitoring with eDNA: metabarcoding across the tree of life in a tropical marine environment. Sci Rep 7:12240. DOI: 10.1038/s41598-017-12501-5

Stat M, John J, DiBattista JD, Newman SJ, Bunce M, and Harvey ES. 2019. Combined use of eDNA metabarcoding and video surveillance for the assessment of fish biodiversity. Conservation Biology 33:196-205.

Stoeck T, Bass D, Nebel M, Christen R, Jones MD, Breiner HW, and Richards TA. 2010. Multiple marker parallel tag environmental DNA sequencing reveals a highly complex eukaryotic community in marine anoxic water. Molecular Ecology 19 Suppl 1:21-31. DOI: 10.1111/j.1365-294X.2009.04480.x

Suter L, Polanowski AM, Clarke LJ, Kitchener JA, and Deagle BE. 2020. Capturing open ocean biodiversity: environmental DNA as an alternative to the continuous plankton recorder. Molecular Ecology. DOI: 10.1111/mec.15587

Swadling KM, McKinnon AD, De'ath G, and Gibson JAE. 2004. Life cycle plasticity and differential growth and development in marine and lacustrine populations of an Antarctic copepod. Limnology and Oceanography 49:644-655.

Taberlet P, Bonin A, Zinger L, and Coissac E. 2018. Environmental DNA: For Biodiversity Research and Monitoring: Oxford University Press. 
746 Thomsen PF, Kielgast J, Iversen LL, Wiuf C, Rasmussen M, Gilbert MT, Orlando L, and

747

748

749

750

751

752

753

754

755

756

757

758

759

760

761

762

763

764
Willerslev E. 2012. Monitoring endangered freshwater biodiversity using environmental DNA. Molecular Ecology 21:2565-2573. DOI: 10.1111/j.1365-294X.2011.05418.x

Tin T, Fleming ZL, Hughes KA, Ainley DG, Convey P, Moreno CA, Pfeiffer S, Scott J, and Snape I. 2008. Impacts of local human activities on the Antarctic environment. Antarctic Science 21:3-33. DOI: 10.1017/s0954102009001722

Vanhove S, Lee HJ, Beghyn M, Gansbeke DV, Brockington S, and Vincx M. 2009. The Metazoan Meiofauna in Its Biogeochemical Environment: The Case of an Antarctic Coastal Sediment. Journal of the Marine Biological Association of the United Kingdom 78:411-434. DOI: 10.1017/S0025315400041539

Vause BJ, Morley SA, Fonseca VG, Jazdzewska A, Ashton GV, Barnes DKA, Giebner H, Clark MS, and Peck LS. 2019. Spatial and temporal dynamics of Antarctic shallow soft-bottom benthic communities: ecological drivers under climate change. BMC Ecol 19:27. DOI: 10.1186/s12898-019-0244-x

Wangensteen OS, Palacin C, Guardiola M, and Turon X. 2018. DNA metabarcoding of littoral hard-bottom communities: high diversity and database gaps revealed by two molecular markers. PeerJ 6:e4705. DOI: 10.7717/peerj.4705 
Figure 1

Map of nearshore benthic sampling sites in the Vestfold Hills, East Antarctica.

Base map produced by the Australian Antarctic Data Centre, and adapted for this study by Helen Achurch (AAD). Sites are coloured as per the ordinations in Figure 5 and 7. 


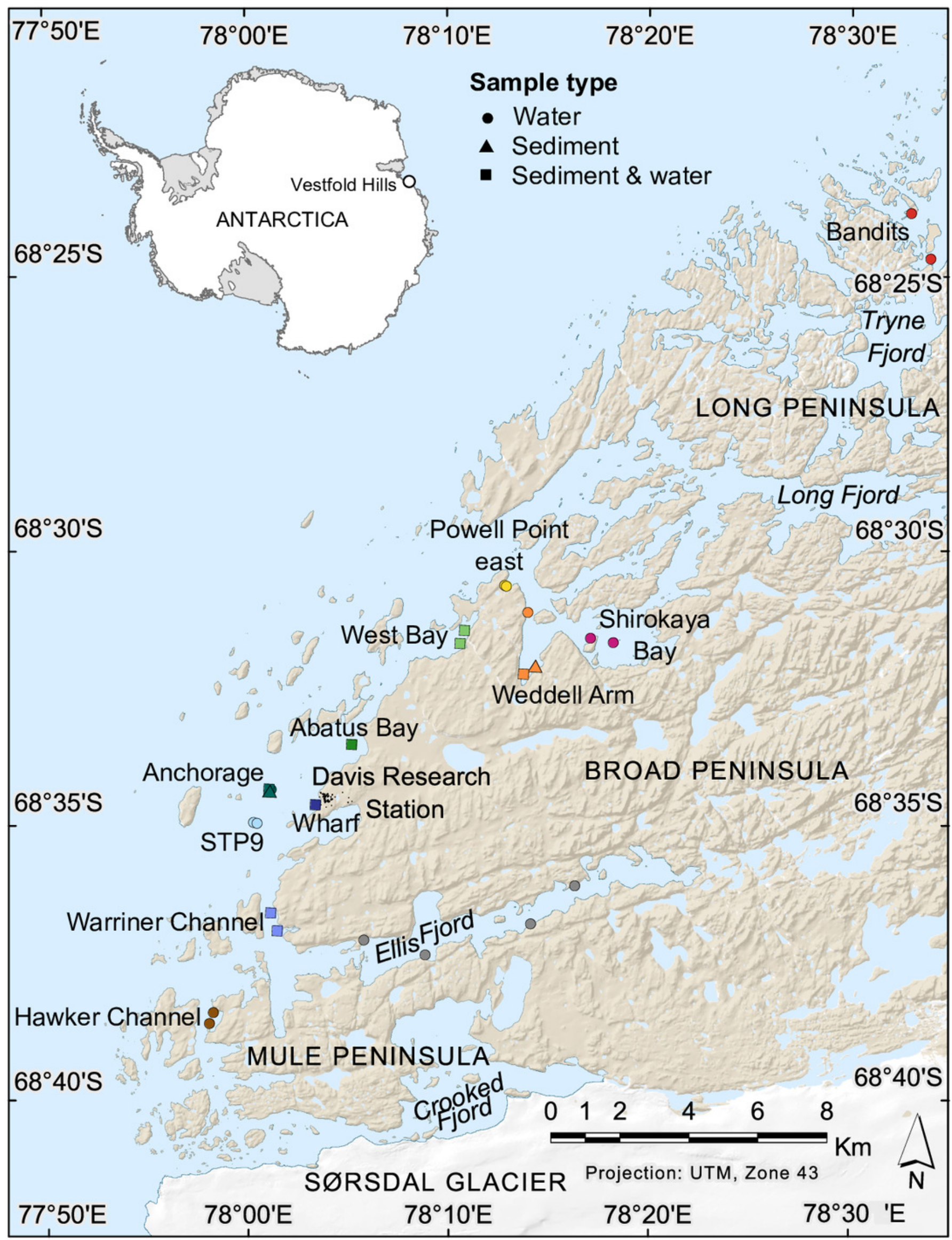




\section{Figure 2}

Number of sequencing reads from the COI marker classified as "metazoan", "nonmetazoan" and "not classified" for sediment and water environmental DNA (eDNA) and samples.

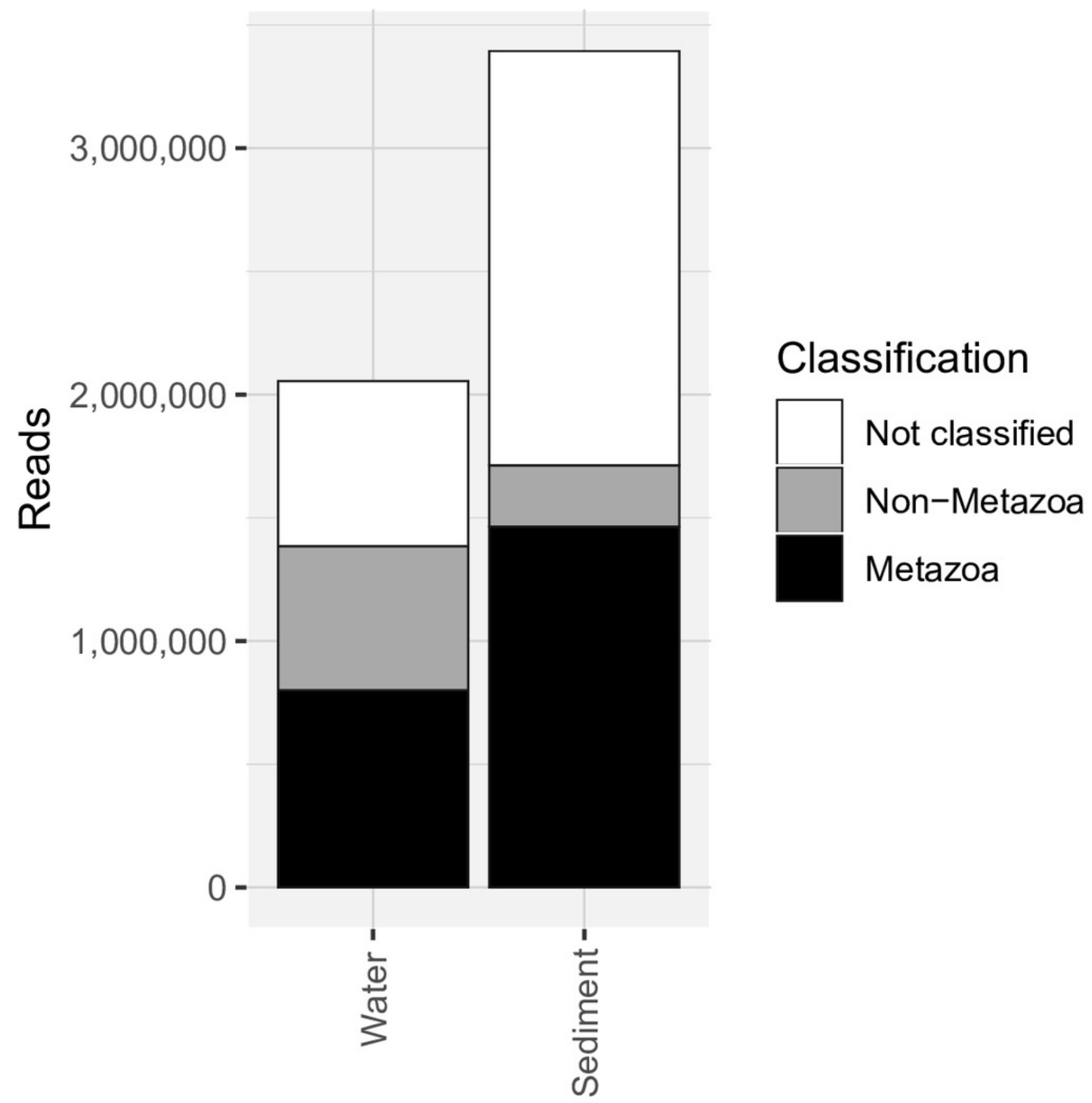




\section{Figure 3}

Number of metazoan species detected per sample by sample type and sediment core section at sites where both sample types were collected, based on 1000 metazoan reads per sample.

The inset shows sample-size based rarefaction curves for all samples. Core samples are classified by core section (1: 0-2 cm, 2: 2-4 cm, 3: 4-6 (or 4-7) cm, 4: 6-8 (7-9) cm, 5: 8-10 $(9-11) \mathrm{cm})$. Cores that were not sectioned are grouped with $0-2 \mathrm{~cm}$ sections.

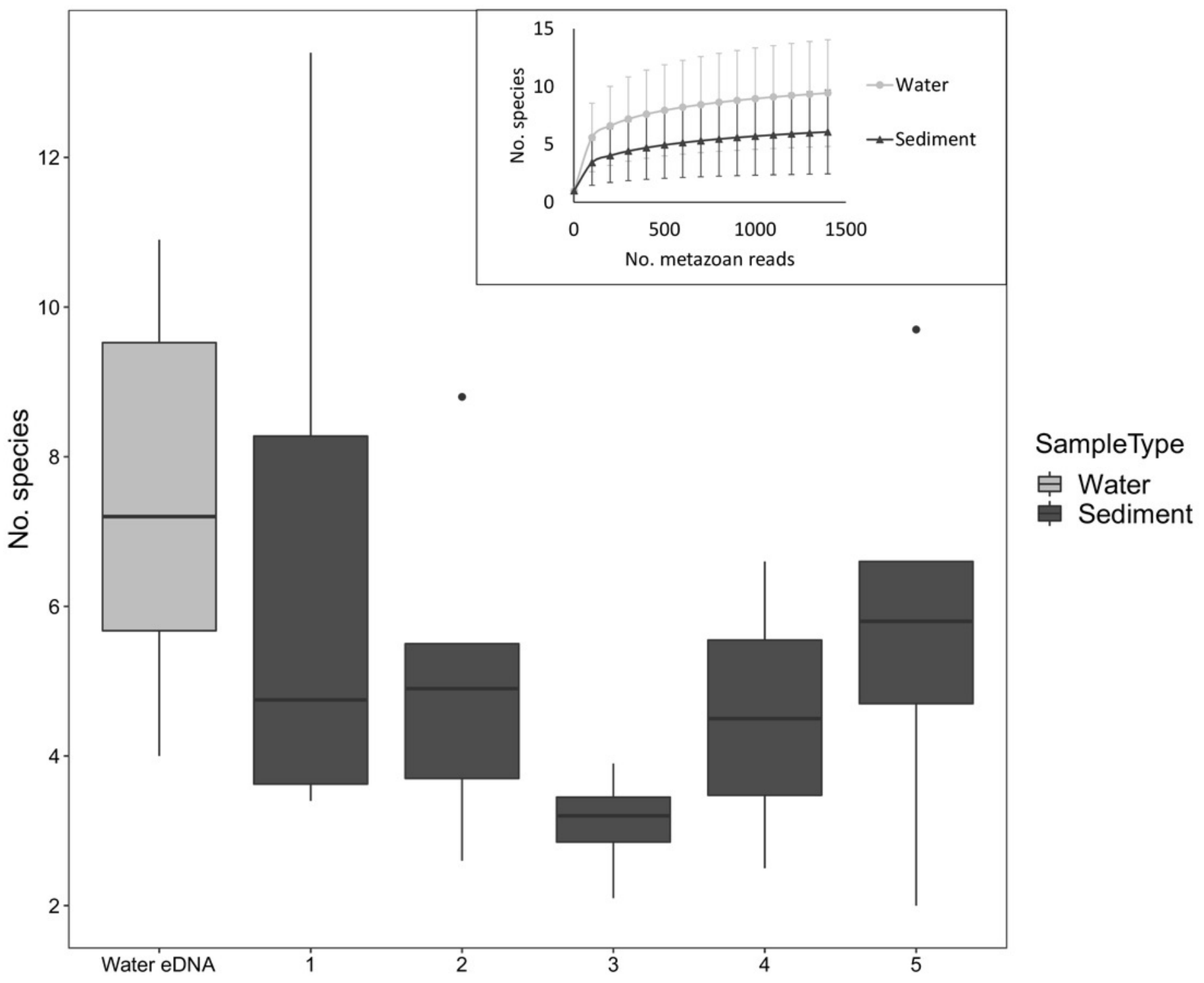


Figure 4

Number of species per metazoan phylum detected exclusively with water eDNA, sediment, or with both methods.

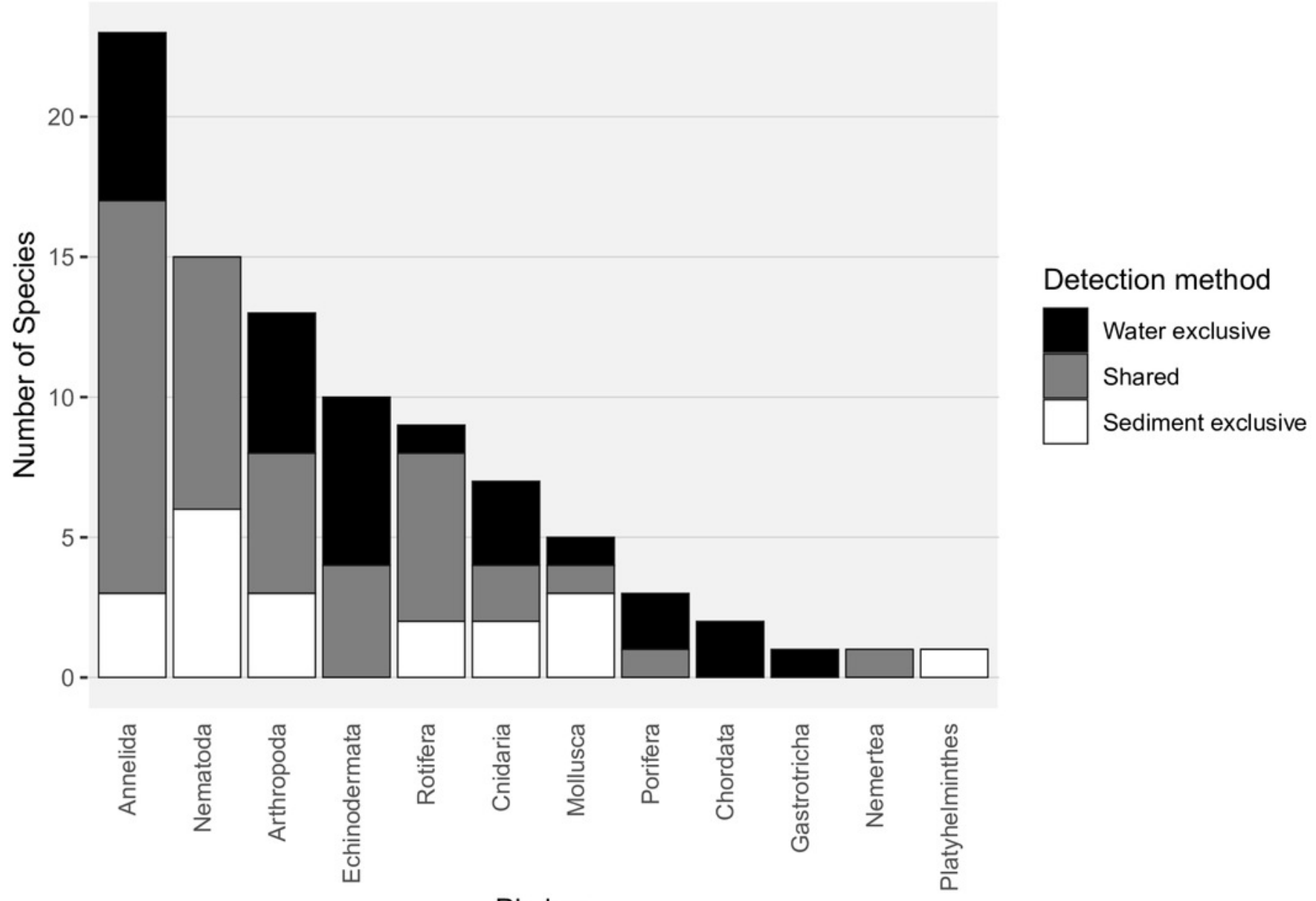

Phylum 
Figure 5

Sediment and water eDNA samples yield distinct benthic metazoan communities.

Non-metric multidimensional scaling (nMDS) plots based on binary Jaccard distances for metazoan communities from sediment and water eDNA samples based on either (A) all samples, or (B) the uppermost sediment sample and water eDNA for locations where both were collected (marked with an asterisk in the legend). Data ellipses drawn based on a multivariate normal distribution with a confidence level of 0.95 .

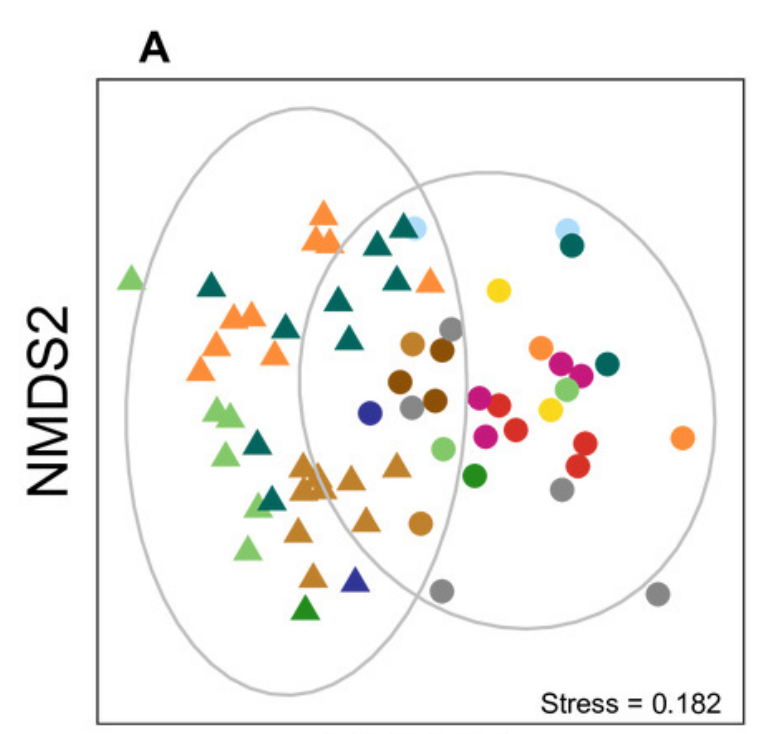

NMDS1
Bandits

- Shirokaya Bay

Weddell Arm*

Powell Point east

West Bay*

- Abatus Bay*

- Anchorage*

- STP9

- Wharf*

- Warriner Channel*

- Hawker Channel

- Ellis Fjord

SampleType

- Water eDNA

A Sediment
B

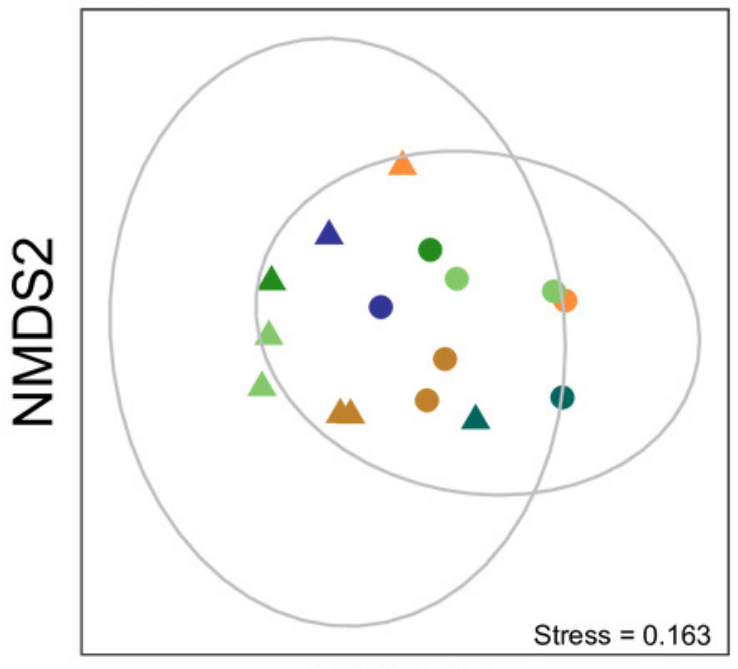

NMDS1 


\section{Figure 6}

Mean taxon relative abundance per sample for sediment and water eDNA samples with more than 1000 reads $(n=66)$.

Taxa with greater than $1 \%$ mean relative abundance in either sample type (representing $96 \%$ of metazoan reads) are shown. Taxa that were significantly more abundant in the paired water eDNA or sediment samples based on Linear Discriminant Analysis (LDA) Effect Size (LEfSe) are indicated with an asterisk.

Paralabidocera grandispina/antarctica* (Arthropoda)

Terebellida sp. A (Annelida) Arthropoda sp. BOLD* (Arthropoda)

Paraonidae sp. A (Annelida)

Hesionidae sp. A* (Annelida) Sterechinus neumayeri* (Echinodermata) Polychaeta BOLD sp. (Annelida) Polynoidae sp. A (Annelida) Nephtyidae sp. A (Annelida) Haplotaxida sp. A (Annelida) Desmodorida sp. C (Nematoda) Polynoidae sp. 212 RG-2014* (Annelida) Paraonidae sp. B (Annelida) Haplotaxida sp. B (Annelida) Ploimida sp. D (Rotifera) Polynoidae sp. C (Annelida)

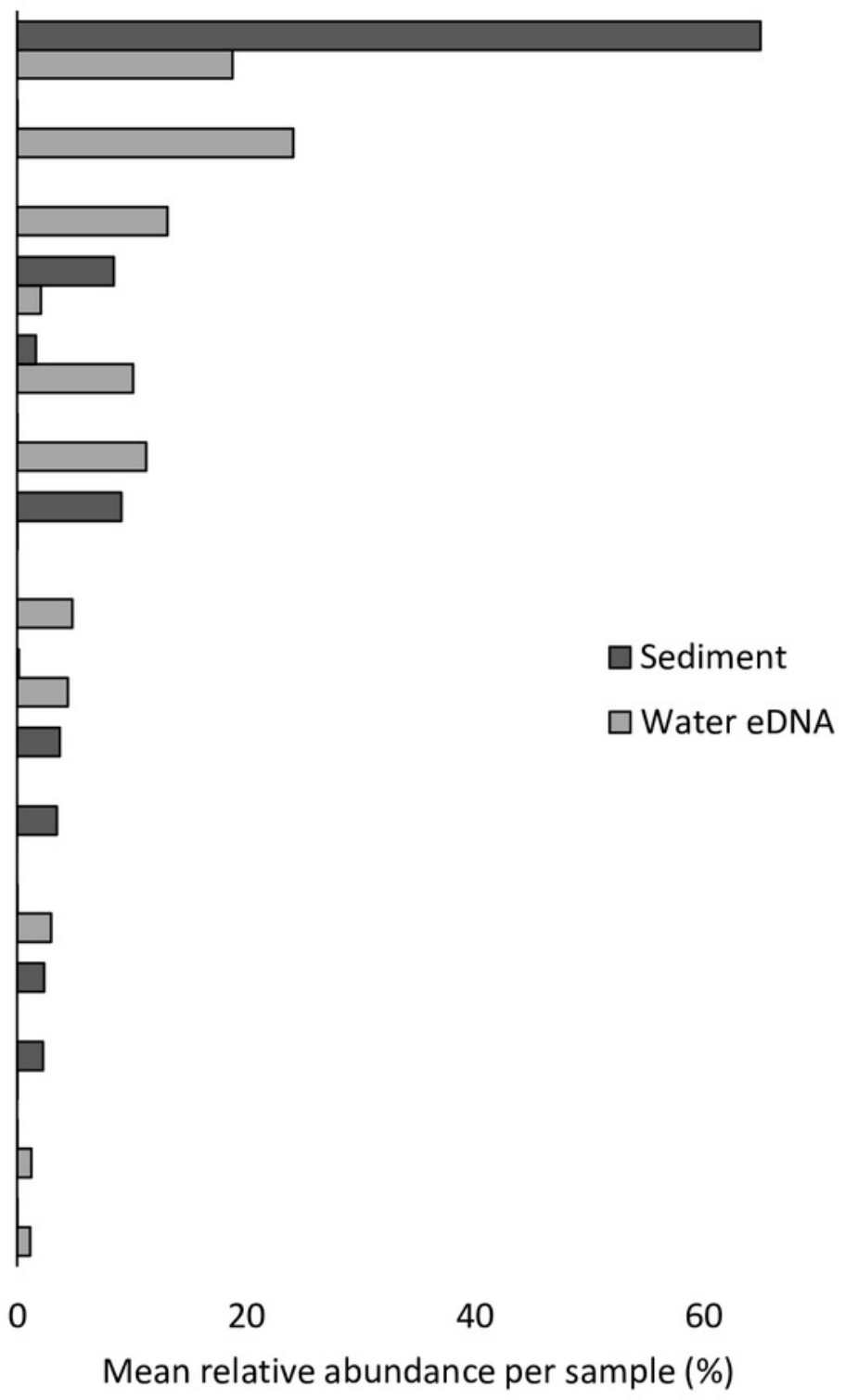


Figure 7

Non-metric multidimensional scaling (nMDS) plots based on binary Jaccard distances for metazoan communities from water eDNA samples.

Vectors show correlations with environmental variables, with vector length proportional to the strength of the correlation.

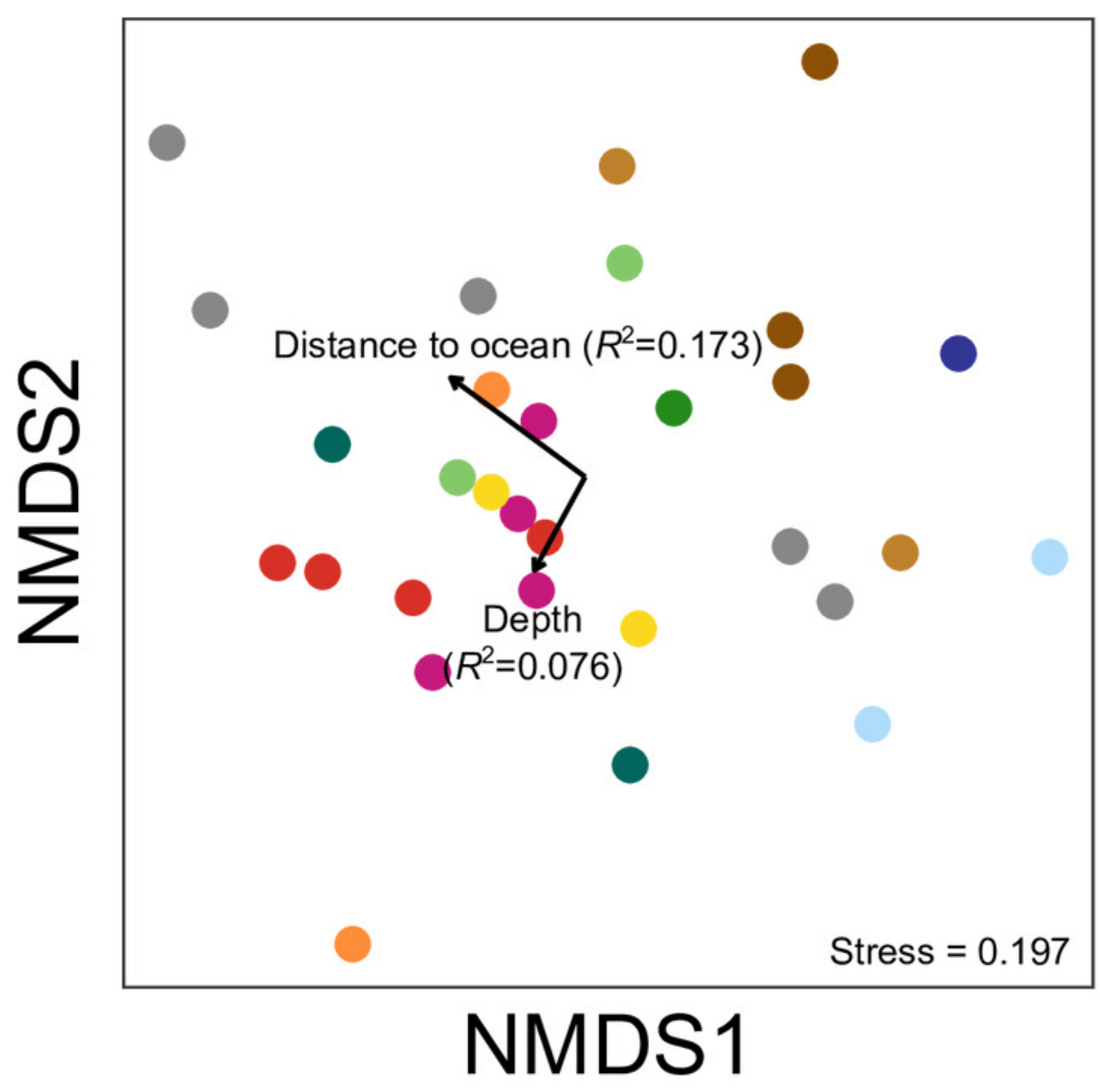

Location

Bandits

Shirokaya Bay

Weddell Arm*

Powell Point east

West Bay*

- Abatus Bay*

Anchorage*

STP9

- Wharf*

- Warriner Channel*

- Hawker Channel

Ellis Fjord 


\section{Table $\mathbf{1}$ (on next page)}

Primers, taxonomic coverage and resolution (species-level) of metabarcodes estimated by in silico PCR against a database of benthic arthropod mitochondrial genomes or complete 18S rRNA gene sequences. 
Table 1. Primers, taxonomic coverage and resolution (species-level) of metabarcodes estimated by in silico PCR against a database of benthic arthropod mitochondrial genomes or complete $18 \mathrm{~S}$ rRNA gene sequences.

\begin{tabular}{|c|c|c|c|c|c|c|}
\hline Name & Locus & Primer sequence (5'-3') & $\begin{array}{l}\text { Mean } \pm \text { SD } \\
\text { length (bp) } \\
\text { (min.-max.) }\end{array}$ & $\begin{array}{c}\text { Species-level } \\
\text { coverage }\end{array}$ & $\begin{array}{l}\text { Species-level } \\
\text { resolution }\end{array}$ & Reference \\
\hline \multirow[t]{2}{*}{ Leray COI } & $\mathrm{COI}$ & GGWACWGGWTGAACWGTWTAYCCYCC & $313 \pm 1$ & $69 / 78(88 \%)$ & $67 / 69(97 \%)$ & Leray et al. (2013) \\
\hline & & TAIACYTCIGGRTGICCRAARAAYCA & $(307-313)$ & & & \\
\hline \multirow[t]{2}{*}{ Sauron COI } & $\mathrm{COI}$ & GGDRCWGGWTGAACWGTWTAYCCNCC & $313 \pm 1$ & $72 / 78(92 \%)$ & 70/72 (97\%) & Rennstam Rubbmark et al. (2018) \\
\hline & & TAIACYTCIGGRTGICCRAARAAYCA & $(307-313)$ & & & \\
\hline \multirow[t]{2}{*}{ Leray-XT } & $\mathrm{COI}$ & GGWACWRGWTGRACWITITAYCCYCC & $313 \pm 1$ & $76 / 78$ (97\%) & $74 / 76(97 \%)$ & Wangensteen et al. (2018) \\
\hline & & TAIACYTCIGGRTGICCRAARAAYCA & $(307-313)$ & & & \\
\hline \multirow[t]{2}{*}{ V4_18S } & $18 \mathrm{~S}, \mathrm{~V} 4$ & CCAGCASCYGCGGTAATTCC & $580 \pm 88$ & 177/192 (92\%) & $175 / 177(99 \%)$ & Stoeck et al. (2010), \\
\hline & & ACTTTCGTTCTTGATYRATGA & $(372-965)$ & & & Piredda et al. (2017) \\
\hline \multirow[t]{2}{*}{ Pera02 } & 18S, V9 & CCCTTTGTACACACCGCC & $147 \pm 17$ & $125 / 192(65 \%)$ & $99 / 125$ (79\%) & Taberlet et al. (2018) \\
\hline & & ATGATCCTTCCGCAGGTTCA & $(131-231)$ & & & \\
\hline \multirow[t]{2}{*}{ Arth02 } & $16 S$ & GATAGAAACCRACCTGGYT & $142 \pm 1$ & $75 / 78(96 \%)$ & $73 / 75$ (97\%) & Taberlet et al. (2018) \\
\hline & & AARTTACYTTAGGGATAACAG & $(139-146)$ & & & \\
\hline \multirow[t]{2}{*}{ Amph01 } & $16 S$ & TTRYNACCTCGATGTTGAATT & $57 \pm 1$ & $76 / 78(97 \%)$ & $68 / 76$ (89\%) & Taberlet et al. (2018) \\
\hline & & GGTYTGAACTCARATCATGTA & $(56-61)$ & & & \\
\hline \multirow[t]{2}{*}{ Ins16S_1 } & $16 S$ & TRRGACGAGAAGACCCTATA & $194 \pm 14$ & $59 / 78(76 \%)$ & $57 / 59(97 \%)$ & Clarke et al. (2014) \\
\hline & & TCTTAATCCAACATCGAGGTC & $(153-212)$ & & & \\
\hline
\end{tabular}

